УДК 930.23

ББК $63.2+63.3(5)$

\title{
Дискуссионные вопросы по оценке материалов переписи 1897 г. как источника по истории казахского народа и Казахстана (обзор историографии)*
}

\author{
Е.А. Брюханова ${ }^{1}$, Н.П. Иванова ${ }^{1}$, К.С. Калиева ${ }^{2}$, Е.Н. Егоренкова ${ }^{3}$ \\ ${ }^{1}$ Алтайский государственный университет (Барнаул, Россия) \\ ${ }^{2}$ Восточно-Казахстанский государственный технический университет \\ им. Д. Серикбаева (Усть-Каменогорск, Казахстан) \\ ${ }^{3}$ Восточно-Казахстанский государственный университет им. С. Аманжолова \\ (Усть-Каменогорск, Казахстан)
}

\section{Discussion Questions on the Evaluation of the 1897 Census Materials as a Source on the History of Kazakh People and Kazakhstan (Review of the Historiography)}

\author{
E.A. Bryukhanova ${ }^{1}$, N.P. Ivanova ${ }^{1}$, K.S. Kalieva ${ }^{2}$, E.N. Egorenkova $^{3}$ \\ ${ }^{1}$ Altai State University (Barnaul, Russia) \\ ${ }^{2}$ D. Serikbayev East Kazakhstan State Technical University (Ust-Kamenogorsk, \\ Kazakhstan) \\ ${ }^{3}$ Sarsen Amanzholov East Kazakhstan State University (Ust-Kamenogorsk, \\ Kazakhstan)
}

На основе работ исследователей выявляются дискуссионные вопросы оценки данных Первой всеобщей переписи населения Российской империи 1897 г. для изучения истории казахского народа и Казахстана. Источниками стали публикации российских и зарубежных исследователей по истории казахского народа и Казахстана, подготовленные по материалам переписи, в том числе погубернские выпуски, общий свод результатов переписи, специальные выпуски по занятиям населения, рабочим и прислуге. Анализируются проблемы разной интерпретации исследователями данных переписи 1897 г. в определении численности казахов и состава населения Казахстана по материалам агрегированных данных, обусловленные рядом факторов: несоответствие исторических и современных административно-территориальных границ; установление этнической принадлежности человека на основании родного языка. Уделяется внимание проблемам сбора и обработки данных, которые, по мнению исследователей, могли повлиять на качество некоторых результатов переписи 1897 г. Делается вывод о том, что отмеченные недостатки в целом не уменьшают значения материалов переписи 1897 г. для истории казахского народа и Казахстана, тем не менее, некоторые опубликованные данные требуют критического подхода и проверки.

Ключевые слова: казахи, Казахстан, перепись 1897, историография, агрегированные данные, дискуссионные вопросы.
The article based on the work of researchers identifies discussion questions on the evaluation of the 1897 census data to study the history of Kazakh people and Kazakhstan. The sources for the preparation of the article were the publications of Russian and foreign researchers on the history of Kazakh people and Kazakhstan, prepared from the materials of the 1897 census: regional issues, a general summary of the census results, special issues on occupations, workers and servants.

The authors of the article analyze the problems of different interpretations by researchers of the 1897 census data in determining the number of Kazakhs and the composition of the population of Kazakhstan based on aggregated data, due to the different factors: the discrepancy between historical and modern administrative and territorial boundaries; establishing the ethnicity of a person based on their native language.

The attention is paid to the problems of data collection and processing, which, on the researchers' opinions, could affect to the quality of some 1897 census results.

It is concluded that these faults in general do not diminish the significance of the 1897 census materials for Kazakh people and Kazakhstan history, however, some published data require a critical approach and verification.

Key words: Kazakhs, Kazakhstan, the 1897 census, historiography, aggregated data, discussion questions.

\section{DOI 10.14258/izvasu(2019)2-09}

\footnotetext{
^Исследование выполнено за счет гранта Российского научного фонда, проект №17-78-10156.
} 
Материалы Первой всеобщей переписи населения Российской империи 1897 г. считаются одними из самых востребованных источников рубежа XIX-XX вв. Популярность переписи 1897 г. обусловлена несколькими факторами: во-первых, обширная программа, состоящая из целого комплекса вопросов, отражающих демографические, социальные и экономические характеристики населения страны; во-вторых, всеобщность охвата, предполагающая учет всех категорий населения; в-третьих, территория, в том числе включающая и окраины, и экспедиционные корпуса; в-четвертых, единовременность проведения.

В то же время перепись 1897 г. неоднократно становилась объектом критики исследователей (вопросы организации и проведения обследования [1], методики сбора, разработки программы, корректности собранных данных [2] и др.). Дополнительные сложности у исследователей и организаторов возникали с данными по территориям, которые отличались какими-либо особенностями (демографическими, социальными, этническими, хозяйственными и др.). В таком контексте представляется интересным изучение направлений использования и определения проблем интерпретации материалов переписи 1897 г., в том числе по отдельным регионам.

Авторами поставлена цель на основе работ исследователей выявить проблемы при использовании данных переписи 1897 г. для изучения истории казахского народа и Казахстана. Источниками для под- готовки статьи стали публикации российских и зарубежных исследователей по истории казахского народа и Казахстана, подготовленные по материалам переписи 1897 г.: погубернские выпуски, общий свод результатов переписи, специальные выпуски по занятиям населения, рабочим и прислуге. Статья основана на структурном подходе, в соответствии с которым опубликованные и первичные материалы переписи рассматриваются как элементы единой структуры - источника, основным методом исследования стал историографический анализ.

Проблемы применения и интерпретации агрегированных данных переписи 1897 г. в исследовательской практике

Сведения по истории казахского народа и Казахстана представлены в материалах переписи 1897 г. по шести областям Центральной Азии, данные опубликованы в погубернских выпусках [3-8], общем своде результатов [9], а также в специальных выпусках по занятиям населения [10], рабочим и прислуге [11]. Целый ряд последующих преобразований административных границ привел к тому, что исторические границы областей (губерний) XIX в. не совпадают с границами современного государства - Республики Казахстан (рис.).

Для решения выявленной проблемы исследователи $[12$, с. $23 ; 13$, с. 13] предложили учитывать следующее: из состава Акмолинской области нужно исключить Омский уезд и Омск, Уральская область включает

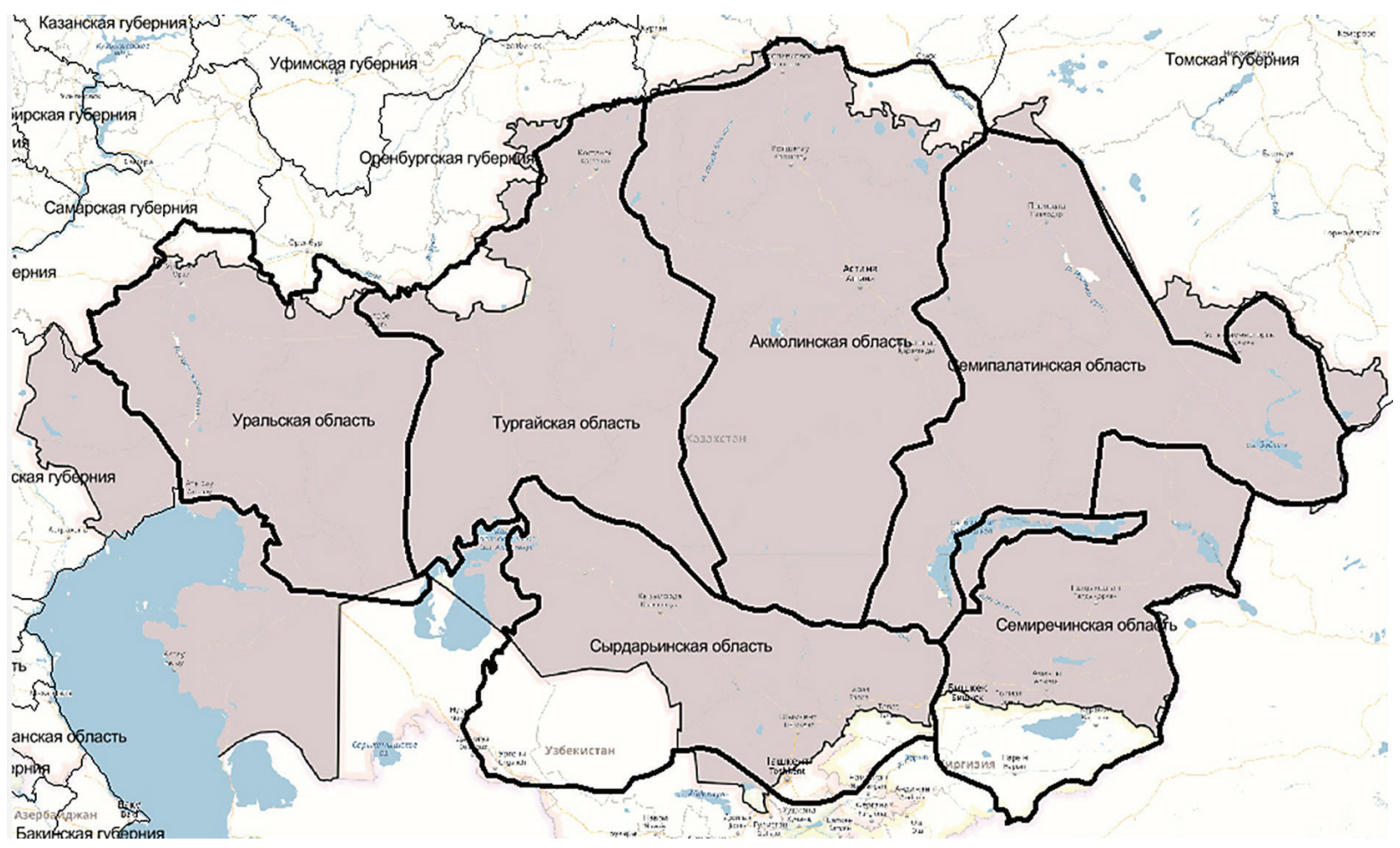

Сопоставление границ областей на 1897 г. и современных границ Республики Казахстан (выделены современные границы Республики Казахстан) 
Букеевскую Орду, Семипалатинская область Павлодарский уезд, из Сырдарьинской области следует исключить Пишпекский и Пржевальский уезды, Мангышлакский уезд включен в Закаспийскую область, а к Тургайской области отнести Кустанайский и Актюбинский уезды [14].

Наиболее обсуждаемым среди исследователей недостатком переписи 1897 г., особенно для «этнических» регионов, в том числе Казахстана, является отсутствие в переписных бланках вопроса о национальности $[12$, с. $23 ; 14 ; 15$, с. 48-49]. Данные о народностях формировались на основе одного вопроса в программе переписи - о родном языке. При этом еще на этапе разработки в Центральном статистическом комитете (ЦСК) стало очевидно, что родной язык «не всегда дает правильное понятие о национальности» [9, т. 2, с.1]. При обработке материалов переписи выяснилось, что в значительной части Туркестана ситуация с определением национальности жителей осложнялась малопонятными сокращениями в переписных листах, обозначающих родной язык, а также заменой местных языковых наречий в графе «родной язык» более общим термином «тюркский» $[9$, т. 2, с. 2].

В историографии традиционно численность казахов рассчитывается на основе данных по группе «киргиз-кайсаки (казаки)» [9; 11]. При этом в разъяснениях к таблицам «Распределение население по родному языку» редактор ЦСК и известный этнограф С.К. Патканов отмечал, что в уездах Семиреченской и некоторых других областях совместно с «кайсаками» учитывались и «киргизы» («кара-киргизы»), так как в переписном материале язык у тех и других был показан как «киргизский» [9, т. 2, с. 26]. На это обратили внимание и исследователи, которые указали на то, что в Семиреченской и Сыр-Дарьинской областях киргизы учтены вместе с казахами $[15$, с. 49; 16].

По подсчетам некоторых авторов $[14 ; 17$, т. 1 , c. 57-58] степень погрешности в учете национального состава населения в материалах переписи 1897 г. была невелика. По замечанию Н.Е. Бекмахановой, процессы ассимиляции и массового усвоения другого языка в регионе еще не получили широкого распространения, что позволяет сделать вывод о том, что «признак родного языка в подавляющем большинстве соответствовал и этническому самосознанию» [17, т. 1, с. 57-58].

Еще одной проблемой, обусловленной несовпадением исторической и современной территорий и сложностями в определении национального состава, является подсчет общей численности казахов и населения Казахстана на рубеже XIX-XX вв. Исследователь С.К. Игибаев в своей статье привел примеры разночтений в определении численности населения Казахстана, в том числе собственно казахов, по работам нескольких авто- ров, таких как Н.В. Алексеенко, А.Н. Алексеенко, M.-А. Х. Асылбекова, А.М. Жаркенова, М. Тынышпаева, каждый из которых называл в качестве источника материалы переписи 1897 г. [16]. По сложившейся в историографии традиции расчет численности населения Казахстана производился на основе данных по шести областям Акмолинской, Семипалатинской, Семиреченской, Сырдарьинской, Тургайской, Уральской. В соответствии с таким подходом Н.Л. Краснобаева указала численность населения Казахстана 4 млн 931 тыс. человек [12, с. 34]. А.Н. Алексеенко и С.К. Игибаев включают в территорию, и соответственно, в состав населения Казахстана Внутреннюю Киргизскую Орду (Астраханская губерния) и Мангышлакский уезд Закаспийской области. В этом случае, по подсчетам А.Н. Алексеенко, численность населения Казахстана составляла 5 млн 136 тыс. человек [18, с. 59]. Численность непосредственно казахов также несколько различается у разных исследователей. А.Н. Алексеенко и Н.Л. Краснобаева, ориентируясь на количество жителей, назвавших в качестве родного языка киргизский, указали, что на территории Казахстана проживало 3 млн 649 тыс. казахов [12, с. 38; 13, с. 60]. По мнению А.И. Кудайбергеновой, численность казахов в Российской империи на рубеже веков составляла 3 млн 881 тыс. человек [19, с. 102]. При этом по подсчетам С.К. Игибаева, который учитывал также «родственных кайсакам» кипчаков, общее количество казахов согласно данным переписи 1897 г. составило 4 млн 91 тыс. человек [16].

В целом, административно-территориальные изменения и развитие этнографии определи наличие в работах исследователей нескольких подходов к определению численности казахов и составу населения Казахстана на рубеже XIX-XX вв.

Недочеты сбора и обработки материалов переписи 1897 г. и их влияние на появление разночтений в работах исследователей

Архивные материалы переписи 1897 г. отражают особенности организации данного статистического мероприятия, сбора и обработки данных о населении империи. Исследователи, изучающие российские и зарубежные архивные документы, отмечали трудности организационной работы статистических комитетов, а также некоторые аспекты проведения переписи, которые могли повлиять на качество собираемых сведений.

Прежде всего следует учитывать, что перепись на территории Казахстана проводилась не только на основании общего для всех регионов «Положения о Первой всеобщей переписи населения Российской империи от 5 июня 1895 г.», но и сучетом «Отступления от общего порядка переписи населения в областях Акмолинской, Семипалатинской, Семиреченской, Тургайской и Уральской от 26 октября 1896 г.», кото- 
рое определило целый ряд особенностей, касавшихся организации переписных участков, периода проведения переписи и сбора данных. Например, в соответствии с «Отступлениями...» перепись кочевого населения должна была быть произведена на переписных листах формы А/Б, причем можно было не заполнять графы о сословии, месте рождения, приписки и постоянного проживания, вероисповедании, побочном занятии и другого[15, с. 37-38, 44-47; 20, с. 63] для населения указанных выше районов. Как в дальнейшем такие (незаписанные) данные должны обрабатываться, инструкции не разъясняли.

Обзор отчетов переписных комиссий позволил исследователям выделить ряд организационно-технических проблем проведения переписи. Как и во многих других регионах Российской империи, для областей современного Казахстана было характерно распространение различных негативных слухов о назначении переписи и слабая разъяснительная работа [21], что приводило к уклонению от переписи и попыткам скрыть истинные сведения о численности и составе семей [12, с. 23]. Из технических проблем Г.Т. Мусабалина отмечала, что счетчики испытывали затруднения в определении типа хозяйств [21], при этом признаки кочевого или оседлого состояния хозяйства в сам переписной лист не вносились и оставались на усмотрение самих счетчиков [15, с. 48]. Некоторые сложности вызывало определение признаков и границ населенного пункта, особенно в сельской местности. Один из авторов данной статьи на основе изучения журналов заседаний областных статистических комитетов отмечала, что населенным пунктом в казахской степи могли считать аул, урочище и даже волость [15, с. 48]. Между тем определение признаков и границ населенных пунктов имело важное значение для производства подчетов численности населения местными статистическими комитетами, но подробных инструкций для этого в архивных материалах исследователями обнаружено не было.

Трудным оказался и вопрос об определении главного и побочного занятия населения, что позволило ряду авторов обозначить проблему выявления социального и профессионального состава населения Казахстана из материалов переписи 1897 г. $[15$, c. $48 ; 21]$. Сравнение опубликованных результатов и сохранившихся первичных материалов переписи показало, что обработка сведений о занятости населения была неудачной в целом для всех регионов Российской империи [2, с. 113]. К сожалению, переписные листы по населению Казахстана в достаточно репрезентативном комплексе не сохранились или еще не обнаружены исследователями. В фонде 536 Семипалатинской уездно-городской переписной комиссии Центрального государственного архива Республики Казахстан было выявле- но всего несколько переписных листов по трем аулам и зимнему стойбищу Семипалатинского уезда [22, л. 186-213]. Однако в Государственном архиве в г. Тобольске отложились переписные листы почти всех казахских аулов Тобольской губернии [23, с. 21]. Это обстоятельство позволило 3.Е. Кабульдинову провести качественное сравнение агрегированных и персональных данных о занятости казахов Тюкалинского и Тарского уездов Тобольской губернии. Исследователь не только отметил ошибку в опубликованных результатах переписи, но и опроверг основанный на ней тезис о переходе казахов от скотоводческого хозяйства к земледельческому на территории Тобольской губернии [23, с. 183-185].

Итак, недостатки в организации и проведении переписи 1897 г., а также ошибки в обработке собранных сведений, по мнению ряда авторов [2, с. 113-114; 23, с. 23], требуют критического подхода к использованию материалов переписи 1897 г. в исторических исследованиях.

\section{Заключение}

Материалы Первой всеобщей переписи населения Российской империи 1897 г. большинством исследователей признаются объективным и достоверным источником, в том числе по истории Казахстана.

При этом в работах встречается несколько подходов к интерпретации агрегированных данных переписи 1897 г. по численности и составу населения Казахстана в конце XIX в. Разные варианты подсчета обусловлены изменениями административно-территориальных границ, а также научных представлений о признаках, позволяющих определять этническую принадлежность.

Кроме того, исследователи указывали на необходимость критического отношения к сведениям переписи 1897 г. в связи с недочетами в сборе и обработке первичных сведений. К организационным сложностям проведения переписи в казахской степи авторы относили разные определения понятия «населенный пункт», пропуски части сведений о социальном положении и занятиях населения, неточности при фиксации переписчиками родного языка, ошибки в указании данных о профессии. Вместе с тем альтернативного достаточного полного и комплексного источника по истории населения Казахстана рубежа XIX-XX вв. в распоряжении исследователей нет.

Таким образом, не умаляя в целом значения материалов переписи 1897 г., можно выделить несколько дискуссионных вопросов, которые следует учитывать при проведении исследований. К проблемным аспектам применения материалов переписи 1897 г. по истории казахского народа и Казахстана можно отнести: сопоставление современных и исторических границ, установление этнической принадлежности населения, а также реконструкцию социального и профессионального состава общества. 


\section{Библиографический список}

1. Сафронов А.А. Из истории подготовки Первой всеобщей переписи населения Российской империи 1897 г. // Документ. Архив. История. Современность. Вып. 1. Екатеринбург, 2001.

2. Литвак К.Б. Перепись населения 1897 года о крестьянстве России (источниковедческий аспект) // История СССР. 1990. № 1.

3. Первая всеобщая перепись населения Российской империи. Т. 81: Акмолинская область. СПб., 1904.

4. Первая всеобщая перепись населения Российской империи. Т. 84: Семипалатинская область. СПб., 1905.

5. Первая всеобщая перепись населения Российской империи. Т. 85: Семиреченская область. СПб., 1905.

6. Первая всеобщая перепись населения Российской империи. Т. 86: Сыр-Дарьинская область. СПб., 1905.

7. Первая всеобщая перепись населения Российской империи. Т. 87: Тургайская область. СПб., 1904.

8. Первая всеобщая перепись населения Российской империи. Т. 88: Уральская область. СПб., 1905.

9. Общий свод по Империи результатов разработки данных первой всеобщей переписи населения, произведенной 28 января 1897 года. Т. I-II. СПб., 1905.

10. Распределение населения по видам главных занятий и возрастным группам по отдельным территориальным районам. T. I-IV. СПб., 1905.

11. Численность и состав рабочих в России на основании данных Первой всеобщей переписи населения Российской империи 1897 г. Т. I-II. СПб., 1906.

12. Краснобаева Н.Л. Население Казахстана в конце XIX - первой четверти XX века. Усть-Каменогорск, 2011.

13. Жумасултанов Т.Ж., Ибраев А.Т. Население Казахстана с древнейших времен до наших дней. Алматы, 2000.

14. Об истории переписей населения в Казахстане / Министерство национальной экономики Республики Казахстан. Комитет по статистике [Электронный ресурс]. URL: stat.gov.kz/getImg?id=WC16200032735 (дата обращения: 27.03.2019).
15. Калиева К.С. Переписи населения как источник для изучения народонаселения Казахстана 1897-1926 гг. Усть-Каменогорск, 2012.

16. Игибаев С.К. Казахи в составе России в конце XIX века: их численность, размещение, занятия и образовательный уровень // Вклад молодых исследователей в индустриально-инновационное развитие Казахстана: сборник материалов. Усть-Каменогорск, 2009 [Электронный ресурc]. URL: https://articlekz.com/article/6768 (дата обращения: 27.03.2019).

17. Бекмаханова Н.Е. Полиэтничное население Казахстана и Киргизии в евразийских миграционных процесcax на рубеже XIX-XX веков // Казахи России: история и современность : материалы Международной научнопрактической конференции : в 2 т. / отв. ред. Ш.К. Ахметова, И.В. Толпеко, Н.А. Томилов. Омск, 2010.

18. Алексеенко А.Н. Республика в зеркале переписей населения // Население и общество. Информационный бюллетень Центра демографии и экологии человека Института народнохозяйственного прогнозирования РАН. 2000. № 47.

19. Кудайбергенова А.И. Население Казахстана: динамика численности и состав (1897-2007 годы) // Казахи России: история и современность: материалы Международной научно-практической конференции: в 2 т. / отв. ред. Ш.К. Ахметова, И.В. Толпеко, Н.А. Томилов. Омск, 2010.

20. Калиева К.С. Документы и материалы архивов об организации и проведении переписей населения на территории Казахстана (1897-1926 гг.) // Известия Алтайского гос. ун-та. 2007. № 4/2.

21. Мусабалина Г.Т. Первая Всеобщая перепись населения Российской империи 1897 года в Семипалатинской области// Qazaqstan Tarihy [Электронный ресурc]. URL: https://e-history.kz/ru/books/library/view/1410 (дата обращения: 28.03.2019).

22. Центральный государственный архив Республики Казахстан. Ф. 536. Оп. 1. Д. 1.

23. Кабульдинов 3.Е. Казахи Тобольской и Томской губерний во второй половине XVIII - начале XX вв. (историко-демогрофический аспект). Павлодар, 2001. 